\title{
Experimental evidence of polymorphysm of sexual development in Capitella sp. B (Polychaeta: Capitellidae) from Barcelona, Spain*
}

\author{
NURIA MÉNDEZ \\ Laboratorio de Invertebrados Bentónicos. Unidad Académica Mazatlán. Instituto de Ciencias del Mar y Limnología, \\ UNAM. PO Box 811. Mazatlán 82000, Sinaloa, México. E-mail: nuri@ola.icmyl.unam.mx
}

\begin{abstract}
SUMMARY: The development and growth of Capitella sp. B obtained from Barcelona were studied under culture conditions. Trochophore and metatrochophore larvae hatched non-simultaneously (two release periods) from single brood tubes. This is the first laboratory evidence of polymorphysm of sexual development in the Capitella capitata species-complex. During the "first release" period, only free swimming trochophores hatched. The females, still bearing larvae inside the brood tube, were transferred to another dish. After three days, ciliated metatrochophores hatched from $8.7 \%$ of the transferred broods. In a culture experiment, larvae maintained in sediment enriched with artificial food grew to immature and mature adults. In this condition, the larvae that hatched during the "first release" reached the immature adult stage, while the larvae derived from the "second release" became mature adults. Oogenesis was observed three times in one female from the second release, though no spawning and fertilization occurred under incubation with sib mature males. Two different sizes of coelomic oocytes were observed. Polymorphysm of sexual development is discussed as an advantageous reproductive strategy enhancing survival in organic enriched sediments.
\end{abstract}

Key words: Polychaeta, Capitella, poecilogony, development polymorphysm, reproduction, Barcelona.

\section{INTRODUCTION}

Capitella capitata is an opportunistic polychaete that has been considered an important universal indicator of organic pollution in marine sediments (e.g. Pearson and Rosenberg, 1978; Méndez et al., 1997; Méndez et al., 2000). Capitella capitata consists of a complex of sibling species differing mainly in allozyme and general protein patterns, ecophysiological characteristics and reproductive modes (Grassle and Grassle 1976; Wu et al., 1991; Gamenick et al., 1998a, 1998b).

\footnotetext{
*Received July 25, 2000. Accepted November 12, 2001.
}

Capitella spp. females construct brood tubes with fecal materials, substrate and potential food, which are open at both ends. The fertilised eggs are placed around the inner surface of the tube and remain there until the trochophore stage. These trochophore larvae have two small eyes and two ciliary rings, which allow free movement inside the tube or in the water column after hatching (Reish, 1974, 1980). The metatrochophore stage can be reached inside the tube or in the water column and has 13 segments and a visible ventral stomodeal concavity, which is not connected to the gut (George, 1984). Ciliated metatrochophores have been observed in several Capitella sibling species (i.e. Reish, 1974; 
George, 1984 Méndez et. al., 2000); on the other hand, Warren (1976a) and Méndez (1995) reported non-ciliated metatrochophores inside the parental tubes and suggested that movements are achieved by longitudinal muscular contractions. The chaetal arrangement in metatrochophores consists of capillaries in the first three segments and hooded hooks in the subsequent segments (Méndez, 1995).

The juvenile stage of Capitella spp. has a vermiform shape with a complete segmentation and a clear distinction between thorax and abdomen. The chaetal arrangement is identical to that of metatrochophore larvae (Méndez, 1995). The thoracic capillary chaetae are posteriorly replaced by hooded hooks identical to those from the abdomen (Warren, 1976b). The mature males are characterised by the presence of genital spines between the $8^{\text {th }}$ and $9^{\text {th }}$ thoracic setigers (Reish, 1980), while ovaries are visible in mature females. The ovaries of most of the C. capitata complex females are paired yellowish sac-like organs, suspended by mesenteries in the ventral coelomic cavity throughout the mid-body segments (Bellan et al., 1972; Eckelbarger and Grassle, 1983). Oocytes mature once they enter the coeloma, where they float freely for a variable period before being spawned by the female. Such mature eggs are spherical and creamy-white to pale yellow (Foret, 1974-75; Eckelbarger and Grassle, 1983; Zhang and $\mathrm{Wu}, 1988)$. Fertilisation occurs either internally or at the time of egg discharge (Reish, 1980). After copulation, the female lays the fertilised eggs around the inner wall of the brood tube where incubation occurs (Tsutsumi and Kikuchi, 1984).

Poecilogony is a polymorphysm of sexual development in some marine invertebrates, in which feeding and non-feeding or planktonic and benthic larvae are produced (Duchêne, 2000). To be a poecilogonous species, a different mode of development has to be found from sibling offspring of a single female, or from different individuals of a single biological species, and the different modes of development cannot be altered by disturbance in laboratory handling (Chia et al., 1996).

Few polychaete species are known to be poecilogonous (Hoagland and Robertson, 1988). Levin (1984) and Chia et al. (1996) found that a single Streblospio benedicti individual can switch reproductive modes and produce both planktotrophic and lecithotrophic larvae. The production of two larval kinds within a single egg capsule was described for Boccardia proboscidea (Blake and Kudenov, 1981) and B. polybranchia (Duchêne, 2000) or in single broods for Cirriformia tentaculata (George, 1967).

With respect to the Capitella species-complex, Chia et al. (1996) observed different development modes in sibling juveniles from a single female of Capitella sp. from Vancouver, Canada. On the West Coast of Scotland, Pearson and Pearson (1991) described two types of $C$. capitata: type 1 (small worms with small number of large eggs) and type 2 (large worms with large number of small eggs). Capitella type 1 larvae might switch to producing type 2 larvae, supporting the poecilogony hypothesis. The first field record of poecilogony in C. capitata was reported by Willcox and Nickell (1998), who found just one brooding female bearing two kinds (type 1 and type 2) of eggs, similar to those previously described by Pearson and Pearson (1991). Unfortunately, hatching and larval development were not described by these authors.

The present study shows experimental evidence of poecilogony with a non-simultaneous release of larvae in Capitella sp. coming from the littoral zone near Barcelona, with a description of the reproductive mode, larval development and growth.

\section{MATERIALS AND METHODS}

During January, 1999, specimens of Capitella sp. (hereafter termed "Capitella sp. B") were collected with a van Veen grab in the littoral zone off Barcelona $\left(41^{\circ} 25^{\prime} \mathrm{N} 2^{\circ} 15^{\prime} \mathrm{E}\right)$ at a depth of $40 \mathrm{~m}$, close to the outlet of wastewater and sludge pipelines. The worms were maintained in stock cultures under laboratory conditions for 4 months. These cultures were aquarium tanks $(20 \times 30 \mathrm{~cm})$ containing a 2 to $4 \mathrm{~cm}$ layer of sediments which had previously been sieved to a grain size less than $250 \mu \mathrm{m}$ in diameter and frozen (11.4\% organic matter), and 1.51 of aereated seawater $\left(30 \%\right.$ o S) maintained at $18^{\circ} \mathrm{C}$. Animals were fed weekly with $0.5 \mathrm{~g}$ per culture of a mixture of equal parts of commercial fish food, baby cereal and dried spinach (Forbes et al., 1996).

Fifteen brood tubes with developing embryos were isolated from the stock culture and placed in dishes containing $1 \mathrm{~g}$ of sediment (grain size: $<250$ $\mu \mathrm{m}$ in diameter) and $7 \mathrm{ml}$ of seawater, and maintained at $18^{\circ} \mathrm{C}$ in the dark. From isolation until hatching, daily observations were carried out using a stereoscopic microscope. Five broods (Broods 1 to 5) were randomly chosen for periodic size measurements of individuals and the duration of every devel- 
opmental stage was calculated. In the case of trochophore and metatrochophore larvae, 3 to 5 individuals were measured and the average body length and width were estimated. After hatching, larvae were counted and size measurements were performed using a micrometer installed in a compound Olympus BH2 (40x) microscope. Due to the different contraction and expansion degrees observed in worms, three replicate measurements of 3 to 5 juveniles and adults were performed to estimate the average length. Five replicate measurements of each brooding female were obtained to calculate the average length. For measurement of juveniles, adults and brooding females a micrometer installed in an Olympus SZ30 (4x) Stereoscopic microscope was used.

In order to observe the effect of organic-enriched sediment on juvenile and adult growth, two different organic content conditions were tested:

a) "Natural sediment". Growth from individuals belonging to three broods (Broods 1, 2 and 3) was recorded under the weekly addition of $0.01 \mathrm{~g}$ (wet weight) of sieved sediment (grain size: $<250 \mu \mathrm{m}$ in diameter).

b) "Organic-enriched sediment". Juveniles and adults were fed with artificial food (Forbes et al., 1996) and growth of two broods was recorded (Broods 4 and 5). A preliminary experiment revealed that one day after the addition of food, both trochophores and metatrochophores died. Adjustments were made and survival and growth were observed when $0.001 \mathrm{~g}$ (dry wet) of artificial food was added weekly to the cultures after the worms had reached the juvenile stage (1.5 month old specimens). During the larval stages, only $0.01 \mathrm{~g}$ (wet weight) of $<250$ $\mu \mathrm{m}$ sieved sediment was added weekly.

Survival (expressed in percentages) was calculated as the relationship between the number of individuals in each developmental stage and the number of individuals in the subsequent developmental stage.

\section{RESULTS}

Results obtained in this study indicated that brooding females from Capitella sp. B showed a non-simultaneous release in which some trochophore larvae abandoned the tube (hereafter termed "first release"), but some other larvae remained inside the brood tube. Such brooding females were transferred to new dishes and after three days, metatrochophore larvae were released from the brood tube (hereafter termed "second release"), all of which survived at least until the juvenile stage. This phenomenon was observed in 13 brood tubes. In contrast, in two broods, large trochophore larvae hatched during the second release period and larvae became metatrochophores but died during settling. During both release periods the number of hatched larvae was variable.

Adults were termed "immature adults" when individuals showed an elongated prostomium with or without small eyes and with at least 5 capillary thoracic setigers, and when the females contained yellowish ovaries in the mid-ventral region. Adults were considered "mature" when males bore genital spines between the $8^{\text {th }}$ and $9^{\text {th }}$ thoracic setigers and females had free floating white coelomic eggs. The duration of each developmental stage was variable (Table 1) and some individuals exhibited two different stages simultaneously.

\section{First release}

Ten to 46 trochophore larvae ( $N=15$ broods) hatched during the first release. They were oval shaped and bore two ciliary rings and two red eyes (Fig 1a). After hatching (day 0) they swam actively in the water column and the swimming speed decreased with time. After day 3 the gut appeared. After day 4 the presence of 13 segments (Fig. 1b) in

TABLE 1. - Duration (days after the "first release") of each developmental stage after the two release periods (more frequent ranges between brackets).

\begin{tabular}{|c|c|c|c|c|}
\hline & \multicolumn{2}{|c|}{ First release } & \multicolumn{2}{|c|}{ Second release } \\
\hline & Range & $\mathrm{N}^{\circ}$ Broods & Range & $\mathrm{N}^{\circ}$ Broods \\
\hline \multicolumn{5}{|c|}{ "NATURAL SEDIMENT" } \\
\hline Trochophores & $0-6(0-3)$ & 15 & $2-6(3)$ & 2 \\
\hline Metatrochophores & $1-20(4-5)$ & 15 & $2-12(4-8)$ & 13 \\
\hline Juveniles & $3-64(6-60)$ & 15 & $4-129(6-60)$ & 13 \\
\hline \multicolumn{5}{|c|}{ "ORGANIC-ENRICHED SEDIMENT" } \\
\hline Juveniles & $7-68$ & 2 & $5-57$ & 2 \\
\hline Immature adults & $69-74$ & 1 & $56-72$ & 2 \\
\hline Mature adults & - & - & $73-104$ & 1 \\
\hline
\end{tabular}


a
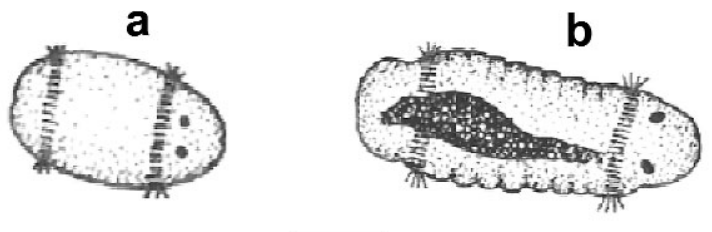

$0.1 \mathrm{~mm}$

FIG. 1. - Capitella sp. B larvae. a) Freshly hatched trochophore from the first release; b) freshly hatched metatrochophore from the second release.

almost all the thochophores from the 15 broods and the chaetal arrangement (three first segments with capillary setae and the subsequent segments with hooded hooks) indicated the transformation to metatrochophore larvae. Such ciliated larvae swam close to the bottom making circular movements and most settled around day 6. A percentage of 9.5 to $60 \%$ (13 broods) of these metatrochopores reached the juvenile stage.

The juvenile stage was characterised by the vermiform shape with a complete segmentation, a clear distinction between thorax and abdomen, the presence of two small eyes, the typical metatrochophore chaetal arrangement and their white color. Between days 28 and 29 , their body became pink and some haemoglobin spots appeared between day 39 and day 47 .

All the juveniles reared under the "natural sediment" treatment died before reaching the adult stage (Figs. 2a and 2b). Immature adults were observed only in brood 4 under the "organic-enriched sediment" treatment (Fig. 3a). On day 62 five capillary setae were observed in the first thoracic segments and the worms were completely red on day 70 . On day 75 yellowish ovaries became visible in the midbody region, which indicated the immature adult stage. No mature adults were observed in the first release individuals.

\section{Second release}

A second release was observed in all 15 brood tubes isolated; from 2 tubes only trochophore larvae were released and from 13 broods only metatrochophore larvae were released. The numbers of hatched trochophores were very different: 6 larvae hatched from brood 3 (Fig. 2c) and 44 larvae from brood 6 (not shown). These larvae hatched three days after the first release, swam slowly in the water column and the gut appeared. The larvae died on day 8 (brood 3; Fig. 2c) and day 4 (brood 6) as metatrochophores that had not settled. In contrast, 15 to 59
Brood 1

a

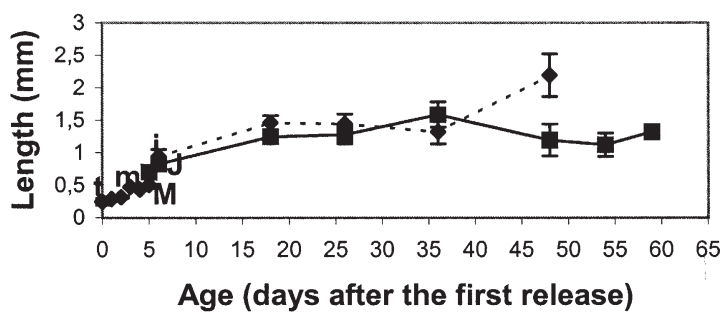

Brood 2

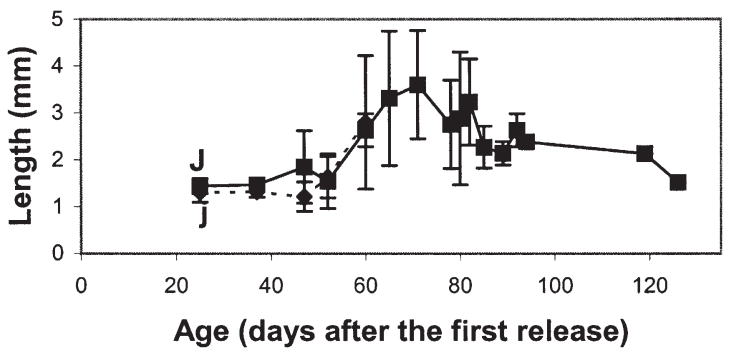

C

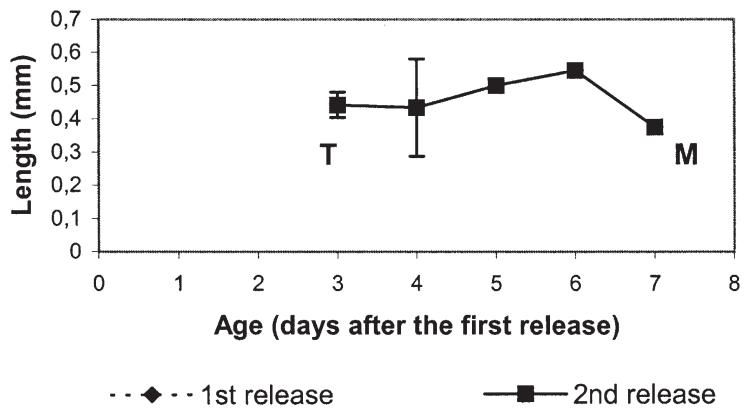

FIG. 2. - Average body length \pm SD over time of individuals in the "natural sediment" treatment. a) metatrochophore larvae and juveniles from brood $1(\mathrm{~N}=5)$; b) juveniles from brood $2(\mathrm{~N}=4$ to 5$)$; $\mathrm{c}$ ) trochophore and metatrochophore larvae of the second release from brood $3(\mathrm{~N}=3)$. ("First release": $\mathrm{t}=$ trochophore stage, $\mathrm{m}=$ metatrochophore stage, $\mathrm{j}=$ juvenile stage; "second release": $\mathrm{M}=$ metatrochophore stage, $\mathrm{J}=$ juvenile stage).

metatrochophore larvae ( $\mathrm{N}=13$ broods) hatched. Their behaviour and morphology were similar to that observed in metatrochophores from the first release (Table 1; Figs. 2a and 3a). A high mortality was observed in metatrochophore larvae (0 to $50 \%$ survival; 12 broods).

A high variability was observed in juvenile development. During the second release individuals became pink on days 28 to 30 and the haemoglobin spots began to be apparent on days 31 to 58. Four capillary setae on the first thoracic segments were observed on days 53 to 71 . None of the juveniles reared in "natural sediment" reached the adult stage (Figs. 2a and 2b).

Juveniles which originated from the second release reached immature and mature adult stages 

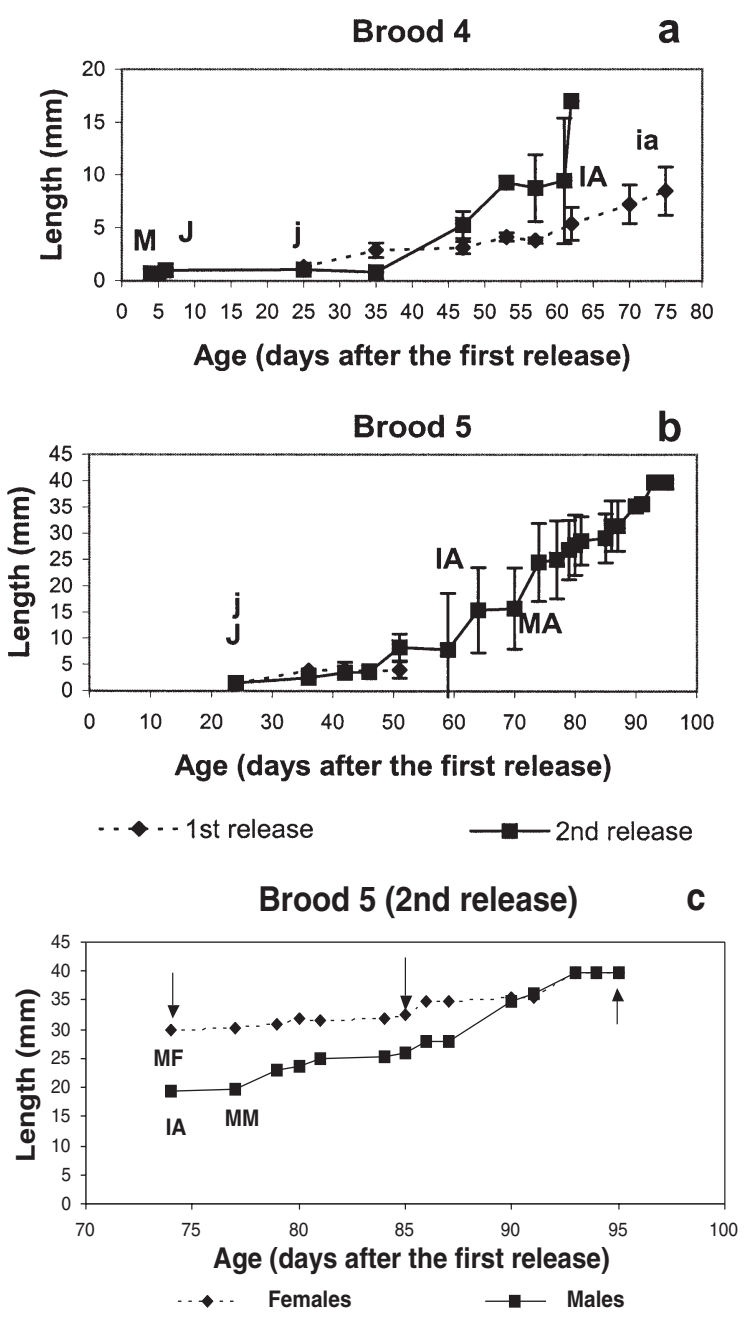

FIG. 3. - Average body length $\pm \mathrm{SD}$ over time of individuals in the "organic-enriched sediment" treatment. a) metatrochophores, juveniles and immature adults from brood $4(\mathrm{~N}=5)$; b) juveniles and immature and mature adults from brood $5(\mathrm{~N}=2$ to 5$)$; c) mature females $(\mathrm{N}=1)$ and males $(\mathrm{N}=1)$ from the "second release" of brood 5. ("First release": j= juvenile stage, ia= immature adult stage; "second release": $M=$ metatrochophore stage, $\mathrm{J}=$ juvenile stage, $\mathrm{IA}=$ immature adult stage, $\mathrm{MA}=$ mature adults, $\mathrm{MF}=$ mature females, $\mathrm{MM}=$ mature males, arrow = appearance of coelomic oocytes $)$.

only under the "organic-enriched sediment" conditions (Figs 3a and 3b). Such individuals bore five capillary setae on the first thoracic segments on day 42 , six capillary setae on days 57 and 58 , and seven capillary setae on days 60 to 64, when yellowish ovary masses appeared. Mature adults $(75 \%$ survival from the immature adult stage) were observed only in brood 5 (Figs $3 b$ and 3c): the only female, bearing white and round coelomic eggs was observed on day 74. Measurements performed by transparency through the body wall indicated the presence of two types of oocytes with two different sizes, i.e. the larger oocytes (mean diameter \pm SD: $0.255 \pm 0.035$ $\mathrm{mm}, \mathrm{N}=10)$ and the small ones $(0.125 \pm 0.20 \mathrm{~mm}$, $\mathrm{N}=10$ ). Fertilisation was not observed and the oocytes were reabsorbed. From days 85 to 90 and days 98 to 102 oocytes appeared again in the coeloma, but fertilisation was not observed. Two mature males, bearing genital spines between the $8^{\text {th }}$ and $9^{\text {th }}$ thoracic segments were recorded on day 77 (Fig 3b). Growth of mature adults was gradual until day 91 when both sexes reached the same size (Fig. 3c). They then maintained it until day 104 when they died, possibly due to anoxia in the culture.

\section{Duration and size of the different developmental stages}

The duration of each developmental stage in both release periods was variable (Table 1); nevertheless, in most of the brooding tubes similar duration ranges were observed for each stage and thus were expressed as the more frequent ranges (between brackets in the table). In general, the trochophore larvae from both release periods spent around 3 days swimming in the water column and the transformation to metatrochophore and juvenile stages was reached simultaneously for the two release periods. The duration of the metatrochophore stage usually varied between 2 and 4 days, but in rare cases, only one larva spent 20 (first release) or 12 days (second release) before metamorphosis to the juvenile stage. Under the "natural sediment" treatment, the duration of the juvenile stage was very long; they survived 64 days in the first release and 129 days in the second release without reaching the adult stage (Fig. 2b). In the "organic-enriched sediment" treatment immature adults originated from the first release survived 74 days, while immature adults from the second release reached maturity on day 73 and survived until day 104. The addition of food into the cultures decreased the developmental time, especially in development from the second release, where the duration of the juvenile stage became shorter.

The trochophore larvae from the first release were significantly smaller $(0.284 \mathrm{~mm}$ body length $)$ than those from the second release $(0.480 \mathrm{~mm}$ body length; t-test for difference between means: $\mathrm{p}<0.05$ ) and the metatrochophores from the second release showed a significantly $(\mathrm{p}<0.05)$ greater size range than those from the first release (Table 2). The mean size recorded for juveniles was not significantly different between both release periods ( $\mathrm{t}$-test, $\mathrm{p}<0.05$ ). Body sizes were overlapped between juveniles and immature adults originating from the first release.

The body length of brooding females was highly variable (range: $7.0-22.83 \mathrm{~mm}$; mean $\pm \mathrm{SD}$ : 
TABLE 2. - Minimum, maximum and average length and width measured in each developmental stage.

\begin{tabular}{|c|c|c|c|c|c|c|}
\hline & $\begin{array}{l}\text { Body length }(\mathrm{mm}) \\
\text { Mean } \pm \text { SD }\end{array}$ & Range (mm) & $\mathrm{N}$ & $\begin{array}{l}\text { Body width }(\mathrm{mm}) \\
\text { Mean } \pm \text { SD }\end{array}$ & Range (mm) & $\mathrm{N}$ \\
\hline \multicolumn{7}{|l|}{ FIRST RELEASE } \\
\hline Trochophores & $0.284 \pm 0.036$ & $0.245-0.315$ & 10 & $0.218 \pm 0.022$ & $0.193-0.235$ & 10 \\
\hline Metatrochophores & $0.473 \pm 0.035$ & $0.437-0.507$ & 9 & $0.261 \pm 0.029$ & $0.237-0.293$ & 9 \\
\hline Juveniles & $2.704 \pm 1.608$ & $0.942-7.231$ & 96 & - & - & \\
\hline Immature adults & $8.467 \pm 2.280$ & $5.767-10.767$ & 5 & - & - & \\
\hline \multicolumn{7}{|l|}{ SECOND RELEASE } \\
\hline Trochophores & $0.480 \pm 0.053$ & $0.442-0.545$ & 8 & $0.235 \pm 0.027$ & $0.195-0.250$ & 8 \\
\hline Metatrochophores & $0.605 \pm 0.138$ & $0.375-0.705$ & 12 & $0.242 \pm 0.054$ & $0.200-0.333$ & 12 \\
\hline Juveniles & $2.795 \pm 2.322$ & $0.817-9.267$ & 106 & - & - & \\
\hline Immature adults & $13.067 \pm 4.145$ & $9.467-17.00$ & 12 & - & - & \\
\hline Mature adults & $29.52 \pm 14.496$ & $19.267-39.770$ & 2 & - & - & \\
\hline
\end{tabular}

16.77 $\pm 4.51 \mathrm{~mm} ; \mathrm{N}=13$ ). No relationship (Pearson’s correlation) was found between the size of females and the number of hatched trochophores $(r=0.252$; $\mathrm{N}=13 ; \mathrm{p}<0.4)$ and metatrochophores $(\mathrm{r}=0.171 ; \mathrm{N}=$ $13 ; \mathrm{p}<0.6)$.

\section{DISCUSSION}

Poecilogony has been conventionally defined for invertebrates as the presence of more than one mode of reproduction within a single species (Hoagland and Robertson, 1988), as multiple development modes (Levin, 1984; Levin et al., 1987), and as the intraspecific variability in the developmental mode (Pearson and Pearson, 1991; Chia et al., 1996). According to Duchêne (2000), peocilogony involves the simultaneous presence of both feeding and nonfeeding planktonic and benthic larvae. On the other hand, peocilogony can also be described based on the genetic variation. Grassle and Grassle (1976) and Grassle et al. (1987) defined separate modes of larval development through the characterisation of separate genotypes and karyotypes. The development mode of Capitella sp. B agrees with the conventional definitions of poecilogony, due to the simultaneous presence of different kind of larvae inside single brood tubes.

The poecilogony hypothesis has been previously suggested for Capitella spp. populations from Scotland (Pearson and Pearson, 1991) and Canada (Qian and Chia, 1992; Chia et al., 1996), since some individuals can switch between different developmental modes and generations in certain environmental conditions. Such authors did not indicate the presence of two types of eggs within a single brood tube. Willcox and Nickell (1998) observed for the first time a single $C$. capitata female bearing two kinds of eggs; nevertheless, a non-simultaneous release of trochophore and metatrochophore larvae has not been previously described for the $C$. capitata complex. Hoagland and Robertson (1988) stated: "there must be cases in which extracellular yolk or nurse nurse-egg production is variable and allows the release of larvae at different stages, but no actual instance is known". Currently, Capitella sp. B constitutes one of these cases.

Trochophores and metatrochophores raised from both releases metamorphosed to juveniles within a short period in Capitella sp. B. This suggests that its development is lecithotrophic, as is that of other Capitella species around the world (summary in Méndez et al., 2000). The poor ability for dispersal permits the proliferation in a reduced area, enhancing local population survival.

Although trochophores derived from the second release were larger than those from the first release, they were not viable, since they died before settling. This suggests that incubation of trochophores inside the brood until the metamorphose to the metatrochophore stage is a good strategy to ensure larval survival. This hypothesis is supported by the fact that metatrochophores hatched in the second release were more resistant since they survived longer and in the case of the "organic-enriched sediment" treatments, they reached the mature adult stage. According to George (1984), retention of larvae inside the brood tube can favour the rapid build-up of the population in situations where food supply is not limiting and therefore, dispersal to new areas is not essential. Moreover, benthic larvae are advantageous when local resources are abundant (Pearson and Pearson 1991), which is the case of Capitella sp. B. Metatrochophores from the second release hatched with a larger size than those from the first release and reached the mature stage successfully. It 
is probable that such larvae growing inside the maternal tube spent less energy and therefore their hatching size was large enough for them to reach the juvenile stage simultaneously to metatrochophores from the first release.

According to Eckelbarger and Grassle (1983), the duration of oogenesis varies from 5 to 7 days in Capitella sp. I and from 40 to 50 days in Capitella sp. IIIa. Capitella sp. B showed an oogenesis duration of about 5 days, similar to Capitella sp. I. Eckelbarger and Grassle (1983) pointed out that the period of coelomic egg storage in the female is minimal when a sexually mature male is present in the culture. The results obtained here did not indicate the same, since although two sib mature males were present in the culture, coelomic oocytes were observed in three time periods but were not spawned and fertilised. This suggests that a mechanism inhibiting fertilisation between sib may be present.

The presence of two different sizes of coelomic oocytes has been demonstrated to be an important evidence of poecilogony. Levin (1984) and Levin et al. (1990) indicated for S. benedicti that planktotrophic development is characterised by small oocytes, while lecithotrophic development is induced by large oocytes. According to this, the presence of oocytes of different sizes produced in the same clutch (as the proportion found between hatched trochophores and metatrochopores) is a good evidence of poecilogony in Capitella sp. B; nevertheless, the oocyte diameters were much smaller than the trochophore sizes, which indicates that these coelomic oocytes may have been at an inmature stage. Unfortunatelly, full-grown oocytes were not observed to ensure enough evidence that small oocytes develop as trochophores and large ones become metatrochophores.

It is well known that in Capitella capitata growth depends strongly on food availability in the environment (Tenore, 1977; Forbes and Lopez, 1990; Tsutsumi et al., 1990). Qian and Chia (1992) concluded that the presence of high amounts of food in the habitat accelerates Capitella sp. growth and the production of offspring and fecundity increases because their generation time becomes shorter. When food becomes limited growth is retarded and thus the generation time increases. This has been confirmed here, since Capitella sp. B specimens reared under "natural sediment" did not reach the adult stage and the juvenile duration was longer (up to 129 days on brood 3). The high larval mortality observed in Capitella sp. B is comparable to data of Vance
(1973) for invertebrates and by Qian and Chia (1994) for Capitella sp. in the field. The high juvenile mortality observed in Capitella sp. B was mainly due to the lack of food. Survival of juveniles under the "organic-enriched sediment" treatment was also low, which suggests that more time was needed to acclimatise the worms to culture conditions.

Data obtained in this study are consistent with data reported in the literature on the life history of the $C$. capitata complex (summary in Méndez et al., 2000). In general terms, the size of females and number of larvae per brood tube are comparable to ranges obtained for several Capitella species by Grassle and Grassle (1976), Gamenick (1997), Zhang and Wu (1988), Wu et al. (1991) and Méndez et al. (2000). The range of length of trochophores in the first release attained the same order of magnitude as that for Capitella sp. from Florida, USA (George, 1984) and C. capitata from Amakusa, Japan (Tsutsumi and Kikuchi, 1984). On the other hand, the extremely large size $(0.442-0.545 \mathrm{~mm})$ from the second release trochophores is only comparable with the size of developing embryos inside the tube previously found in the Barcelona population (0.35-0.44 mm; Méndez, 1995). The size of metatrochophore larvae hatched in both the first and the second release periods is comparable to most of the Capitella species reported in the literature. The size of females, number of larvae per brood and metatrochophore size from the two release periods are similar to those reported for specimens from Barcelona during 1991-92 (Méndez, 1995).

The developmental pattern described here for Capitella sp. B suggests that this is not the same population as $C$. capitata previously studied off the coast of Barcelona during 1991-92 by Méndez (1995). In that study on preserved embryos inside brood tubes, the metatrochophores did not bear ciliated rings and consequently, a completely nonpelagic development was suggested. In contrast, the Capitella population analysed in this study showed a different developmental pattern, with trochophore and ciliated metatrochophore larvae hatching out of the brood tubes and swimming in the water column.

Different developmental modes have been described within the $C$. capitata species complex in the field and in the laboratory. This is the first study to show poecilogony as a reproductive strategy in specimens reared in the laboratory. Further research is recommended focusing on the developmental mode of Capitella sp. B under natural conditions to 
support field evidence of polymorphysm of sexual development in this species.

\section{ACKNOWLEDGEMENTS}

This study was supported by the University of Stirling, Scotland and the Dirección General de Apoyo al Personal Académico, UNAM, Mexico. I want to thank Donald Baird (head of the Environment Group, Institute of Aquaculture, University of Stirling) for the facilities to carry out the experimental work and for his advice. The collection of samples was possible thanks to Jordi Flos (Department of Ecology, Faculty of Biology, University of Barcelona, Spain). I am also grateful to Valery Forbes, Inez Linke-Gamenick (Department of Life Sciences and Chemistry. Roskilde University, Denmark) and Neil Duncan (CIAD, Mazatlán, Mexico) for their comments on the written manuscript.

\section{REFERENCES}

Bellan, G., D.J. Reish and J.P. Foret. - 1972. The sublethal effects of a detergent on the reproduction, development and settlement in the polychaetous annelid Capitella capitata. Mar. Biol., 14: 183-188.

Blake, J.A. and J.D. Kudenov. - 1981. Larval development, larval nutrition, and growth for two Boccardia species (Polychaeta: Spionidae) from Victoria, Australia. Mar. Ecol. Progr. Ser., 6: 175-182.

Chia, F.S., G. Gibson and P.Y. Qian. - 1996. Poecilogony as a reproductive strategy of marine invertebrates. Oceanologica Acta, 19(3-4): 203-208.

Duchêne, J.C. - 2000. Effects of poecilogony and delayed larval emission on recruitment of subantarctic population of Boccardia polybranchia (Polychaeta: Spionidae). Bull. Mar. Sci., 67(1): 311-319.

Eckelbarger, K.J. and J.P. Grassle. - 1983. Ultrastructural differences in the eggs and ovarian follicle cells of Capitella (Polychaeta) sibling species. Biol. Bull., 165: 379-393.

Foret, J.P. - 1974-75. Étude des effets a long terme de quelques détergents sur la séquence du développement de la polychette sédentaire Capitella capitata (Fabricius). Tethys, 6: 751-778.

Forbes, T.L. and G.R. López. - 1990. The effect of food concentration, body size, and environmental oxygen tension on the growth of the deposit-feeding polychaete, Capitella capitata species 1. Limnol. Oceanogr., 35: 1535-1544.

Forbes, V.E., T.L. Forbes and M. Holmer. - 1996. Inducible metabolism of fluoranthene by the opportunistic polychaete Capitella sp. I. Mar. Ecol. Progr. Ser., 132: 63-70.

Gamenick, I. - 1997. Ökophysiologische und enzymatische Differenzierung verschiedener Geschwisterarten des Capitella capitata - Komplexes (Annelida, Polychaeta). Ph.D. thesis. Faculty of Biology. University of Hamburg, $112 \mathrm{pp}$.

Gamenick, I., M. Abbiati and O. Giere. - 1998a. Field distribution and sulphide tolerance of Capitella capitata (Annelida: Polychaeta) around shallow water hydrothermal vents off Milos (Aegean Sea). A new sibling species? Mar. Biol., 130: 447-453.

Gamenick, I., B. Vismann, M.K. Grieshaber and O. Giere. - 1998b. Ecophysiological differentiation of Capitella capitata (Polychaeta). Sibling species from different sulfidic habitats. Mar. Ecol. Progr. Ser., 175: 155-166.

George, J.D. - 1967. Cryptic polymorphism in the cirratulid poly- chaete Cirriformia tentaculata. J. Mar. Biol. Assoc. U. K., 47: 75-80.

George, J.D. - 1984. The behaviour and life history of a mangrovedwelling capitellid (Polychaeta). In: P.A. Hutchings (ed.), Proceedings of the First International Polychaete Conference. Sydney Australia, pp. 323-337. Milsons Point: The Linnean Society of New South Wales.

Grassle, J.P. and J.F. Grassle. - 1976. Sibling species in the marine pollution indicator Capitella (Polychaeta). Science, 192: 567-569.

Grassle, J.P., C.E. Gelfman and S.W. Mills. - 1987. Karyotypes of Capitella sibling species, and of several species in the related genera Capitellides and Capitomastus (Polychaeta). Bull. Biol. Soc. Wash., 7: 77-88.

Hoagland, K.E. and R. Robertson. - 1988. An assessment of poecilogony in marine invertebrates: phenomenon or fantasy? Biol. Bull., 174(2): 109-125.

Levin, L.A. - 1984. Multiple patterns of development in Streblospio benedicti Webster (Spionidae) from three coasts of North America. Biol. Bull., 166: 494-508.

Levin, L.A. and D.V. Huggett. - 1990. Implications of alternative reproductive modes for seasonality and demography in an estuarine polychaete. Ecology, 71(6): 2191-2208.

Méndez, N. - 1995. Non-pelagic development of Capitella capitata (Polychaeta) in the littoral zone of Barcelona, Spain. Sci. Mar., 59: 95-101.

Méndez, N., J. Romero and J. Flos. - 1997. Population dynamics and production of the polychaete Capitella capitata in the littoral zone of Barcelona (Spain, NW Mediterranean). J. Exp. Mar. Biol. Ecol., 218: 263-284.

Méndez, N., I. Linke-Gamenick and V.E. Forbes. - 2000. Variability in reproductive mode and larval development within the Capitella capitata species-complex. Invetebr. Reprod. Dev., 38: 131-142.

Pearson, M. and T.H. Pearson. - 1991. Variation in populations of Capitella capitata (Fabricius, 1780) (Polychaeta) from the West coast of Scotland. Ophelia Suppl, 5: 363-370.

Pearson, T.H. and R. Rosenberg. - 1978. Macrobenthic succession in relation to organic enrichment and pollution of the marine environment. Oceanogr. Mar. Biol. Ann. Rev., 16: 229-311.

Qian, P. and F.S. Chia. - 1992. Effects of diet type on the demographics of Capitella capitata (Annelida: Polychaeta): Lecithotrophic development vs planktotrophic development. $J$. Exp. Mar. Biol. Ecol., 157: 159-179.

Qian, P. and F.S. Chia. - 1994. In situ measurement of recriutment, mortality, growth, and fecundity of Capitella sp. (Annelida: Polychaeta). Mar. Ecol. Progr. Ser., 111: 53-62.

Reish, D.J. - 1974. The establishment of laboratory colonies of polychaetous annelids. Thalass. Jugosl., 10: 181-195.

Reish, D.J. - 1980. Use of polychaetous annelids as test organisms bioassay experiments. In: A.L. Buikema, Jr. and J. Cairns, Jr. (eds.), Aquatic Invertebrate Bioassays, ASTM STP 715, pp. 140-154. American Society for Testing and Materials.

Tenore, K.R. - 1977. Growth of Capitella capitata cultured in various levels of detritus from different sources. Limnol. Oceanogr., 22: 936-941.

Tsutsumi, H. and T. Kikuchi. - 1984. Study of the life history of Capitella capitata (Polychaeta: Capitellidae) in Amakusa, South Japan, including a comparison with other geographical regions. Mar. Biol., 80: 315-321.

Tsutsumi, H., S. Fukunaga, N. Fujita and M. Sumida. - 1990. Relationship between growth of Capitella sp. and organic enrichment of the sediment. Mar. Ecol. Progr. Ser., 63: 157-162.

Vance, R.R. - 1973. On reproductive strategies in marine benthic invertebrates. Am. Nat., 107(955): 339-352.

Warren, L.M. - 1976a. A population study of the polychaete Capitella capitata in Plymouth. Mar. Biol., 38: 209-216.

Warren, L.M. - 1976b. A review of the genus Capitella (Polychaeta, Capitellidae). J. Zool., 180: 195-209.

Willcox, M.S. and T.D. Nickell. - 1998. Field evidence of poecilogony in Capitella capitata. Ophelia, 49: 141-145.

Wu, B.L., P.Y. Qian and S.L. Zhang. - 1991. Morphology, Reproduction, Ecology and allozyme electrophoresis of three Capitella sibling species in Qingdao (Polychaeta: Capitellidae). Ophelia Suppl., 5: 391-400.

Zhang, S.L. and B.L. Wu. - 1988. Taxonomy of the Capitella capitata complex (Polychaeta). Mar. Sci. Bull., 1: 187-192

Scient. ed.: T. Kikuchi 